\title{
EFFECT OF POLLUTION ON FRESHWATER FISHERIES
}

\author{
R. V. Tijare and P. M. Telkhade \\ Institute of Science, Nagpur, (MS), India.
}

Arts, Commerce \& Science College, Tukum, Chandrapur, (MS), India.

Corresponding author: rvtijare@rediffmail.com ptelkhade@yahoo.in

Effect of pollution on the aquatic ecosystems are the most difficult to establish and evaluate. Each environment is somewhat different, but the species inhabiting any given environment have evolved over long period of time and each individual species in a community play its own role. Any additional stress, whether natural or manmade, will tend to eliminate some species, leaving only the more resistant and tolerant forms to survive. The effect may be either direct on the species involved or indirect by the elimination of a food supply. For some of the species in the system the result may be beneficial, through the removal of predators or by stimulated and accelerated growth of their prey.

Due to inappropriate water management and irrigation technology, water run - off from fields to adjacent rivers wetlands and lakes is common. This run off however does not only contain soil sediments but also pesticides residues, salts and fertilizers. Surface runoff can also lead to contamination by fertilizers of rivers, lakes and wetlands. In contrast with pesticides, fertilizers are not directly toxic but instead alter the nutrient system and in consequence the species composition of a specific freshwater ecosystem. Their most dramatic effect is eutrophication of water body i.e. an explosive growth of algae which causes disruption to the biological equilibrium, including killing fish.

Fresh water ecosystems are essential for human as well as species survival. These ecosystems are home of most of the fish species. Despite their value and importance, many lakes, rivers and wetlands around the world are being severely damaged by human activities and are declining at much faster rate than terrestrial ecosystems. More than $20 \%$ of the known freshwater 
species have become extinct or imperiled in recent decades. Watersheds, which catch precipitation and channel it to streams and lakes are highly vulnerable to pollution.

In most cases however adequate information is not available to assess the total biological effects. If severe damage occurs due to eutrophication of a lake or mass mortality of fish the effects will be the one of the evident of pollution. Pollution is however a dangerous process which may contribute for years with no apparent effects until the rate of discharge exceeds the capacity of the system to recover.

Pollution may interfere the normal migration patterns of organisms. The chemotaxis plays an important role in this. Most of the fishes leave their home stream or natural habitats due to pollution. Day to day behavior of species may also be mediated by means of chemotaxis responses. Pollution interfering with the chemoreceptor of the organisms would interfere with behavioral pattern of the species i.e. feeding and mating behavior. Long term exposure to sublethal concentrations of pollution may make an organism more susceptible to disease. It is also possible that some organic pollutants may provide an environment suitable for the development of disease producing bacteria or viruses. In such cases, even though the pollutant is not directly toxic to the adult organism it could still have a profound effect on the species over a long period of time.

The life cycles of the various fish species also disturbs due to pollution in their habitats. The larval forms of many species of fishes are much more sensitive to pollution than the adults. The millions of eggs are produced and fertilized, but only few of the larvae produced and attaining the maturity and also causing the pre adult mortality due to unfavorable conditions. An additional stress on the developing larvae might cause failure of enough individuals to survive and maintain the population of species interrupting any stage of life cycle can be as disastrous for the population as death of the adults from acute toxicity of the surrounding environment. 
Due to solubility of toxic substances in water respiration and certain physiological processes of fishes might also be adversely affected; specially mercury is a general protoplasmic poison and mostly damages the nervous system of organisms.

Pollutants may affect the nutrition i.e. ability to find the prey and digestion or assimilation of the food. Many pollutants produce genetic effects which can have long range significance for the survival of species. Radioactive contamination can cause mutation directly by the action of radiation on the genetic material. Oil and other organic pollutants may include both mutagenic and carcinogenic compounds.

Pesticides are found as common contaminants in soil, air, water and on non target organisms in our urban landscapes. Once there they can harm plants and animals ranging from beneficial soil microorganisms and insects, non target plants, fish, birds and other animals. Chlorpyrifos is a common contaminant of urban streams is highly toxic to fish and has caused fish kills in aquatic ecosystems. Herbicides can also be toxic to fish, widicides also highly toxic to both cold and warm water fisheries. Some herbicides may produce sublethal effects on fish that decreases their chances for survival and threaten the population of species. Herbicide like 2, 4 - D caused physiological stress responses and reduced food gathering capacity in many fishes.

The study of effect of pollution on freshwater ecosystems may be undertaken by considering pollution as an additional stress on the mechanism that keep ecosystem organized. Unless the living part of an ecosystem are already under marked external stress the early effects of the introduction of toxic pollutants will involve only the extinction of particularly susceptible species leaving the more resistant form in a somewhat disorganized community. In communities already under stress, relatively low levels of pollution may cause them to break down or be transformed, with obvious unpleasant symptoms. 
All toxic chemicals (Pesticides, Herbicides and Widicides) are often considered a quick, easy and inexpensive solution for controlling weeds and insect pests in urban landscapes. However pesticide use comes at a significant cost. Pesticides have contaminated almost every part of our environment. Pesticide residues are found in soil and air, and in surface and ground water across the country and urban pesticide uses contribute the problem. Pesticide contamination poses significant risks to the environment and non target organisms ranging from beneficial soil, microorganisms, insect, plants, fishes and birds. Contrary to common misconceptions, even herbicides can cause harm to the environment. In fact weed killers can be especially problematic because they are used relatively large volumes nowadays. The best way to reduce pesticide contamination and the harm it causes in our environment is for all of us to do our part to use safer, non chemical pest control methods.

\section{References:}

Ackhfors, H., Lofroth, G. \& Rosen C.G, (1970): A survey on mercury pollution problem in Sweden with special reference to fish. Oceanogr Mar. Bio., 8, 203-224.

Andreu,V. \& Pico'Y (2004): Determination of pesticides and their degradation products in soil, critical review and comparison of methods. Trends Anal. Chemistry, 23 (10-11), 772-789.

Behera, B. \& Singh, S.G. (1999): Studies on weed management in monsoon season crop of Tomato, Indian J. Weed Science, 31 (1-2), 67.

Butler, P.A. (1966): Monitoring pesticide pollution. Bioscience, 19 (10), 889891.

Folmar, L.C., Sanders, H.O. \& Julin, A.M. (1979): Toxicity of herbicide glyphosate and several of its formulation to fish and aquatic invertebrates. Arch Environ. Contam. Toxicol., 8, 269-278.

Gupta, S.K.,Jani, J.P., Saiyed, H.N. \& Kashyap, S.K. (1984): Health hazards in pesticide formulators exposed to combination of pesticides. Ind. J. Med. Res. 79, 666 
Hasler, A.D. (1969): Cultural eutrophication is reversible, Bioscience, 19 (5), 425-438.

Kannan, K., Tanabe, S., Tatsukawa, R. \& Sinha, R.K. (1994,b): Biodegradation capacity and residue pattern of organochlorines in Ganges river dolphins from India. Toxicol. Environ. Chem. 42, 249-261.

Kannan, K., Tanabe, S. \& Tatsukawa, R. (1995): Geographical distribution and accumulation features of organochlorine residues in fish in tropical Asia and Oceania. Environmental Sci. Tech. 29, 2673-2683.

Kole, R.K. \& Bagchi, M.M. (1995): Pesticide residues in the aquatic environment and their possible ecological hazards. J. Inland Fish. Soc. India. 27 (2), 79-89.

Koyama, J. (1996): Vrtebral deformity susceptibilities of marine fishes exposed to herbicide. Bull. Environ. Contam. Toxicol, 56, 655-662.

Mathur, S.C. (1999): Future of Indian pesticides industry in next millennium. Pesticide Information. 24 (4), 9-23.

Moorman, T.B. (1989): A review of pesticide effects on microorganisms and microbial processes related to soil fertility. Jour. Prod. Agri. 2 (1), 14-23.

Pollution an international problem for fisheries (1971): FAO Fisheries Series 4, $1-85$.

Ramesh, A., Tanabe, S., Iwata, H., Tatsukawa, R., Subramanian, A.N., Mohan, D., \& Venugopalan, V.K. (1990): Seasonal variation of persistent organochlorine insecticide residues in Vellar River waters in Tamil Nadu, South India. Environ. Pollut. 67, 289-304.

Shafiei, T.M. \& Costa, H.H. (1990): The susceptibility and resistance of fry and fingerlings of Oreochromis mossambicus (Peter) to some pesticides commonly used in Shrilanka. J. Appl. Ichthyol. 6, 73-80.

Wadhwani, A.M. \& Lall, I.J. (1972): Harmful effects of pesticides. New Delhi, Indian Council of Agricultural Research, Report of special committee of ICAR, p. 44. 